\title{
In situ view of magma- carbonate interactions in the Jurassic Bonanza arc, Vancouver Island
}

\author{
RebecCa A. Morris* AND DANTE CANIL
}

University of Victoria, Victoria, British Columbia, V8P 5C2

(*correspondence: ramorri@uvic.ca)

Recent studies suggest that a significant amount of $\mathrm{CO}_{2}$ released at arc volcanoes may originate from 'upper plate' carbonate crust, rather than sourced from the mantle, possibly challenging some assumptions about the long term C cycle [1-4]. An in situ plutonic window to view and understand such magma-carbonate interactions are well-exposed in the Jurassic Bonanza arc on Vancouver Island (British Columbia), built on an Upper Triassic carbonate platform.

The Merry Widow Mountain area exposes contacts between arc magma and carbonate on a variety of scales ( $\mathrm{km}$ to $\mathrm{m}$ ). Our mapping and whole-rock chemistry show late-stage dikes that have transited a $\sim 1 \mathrm{~km}$ thick carbonate platform have distinct textures with abundant ocelli-like spherules rich in Ca-phases (i.e., diopside, anorthite). The dikes are on a unique geochemical trend in comparison to other Bonanza arc rocks, with increases in $\mathrm{Ca}$, decreases in $\mathrm{Na}, \mathrm{P}, \mathrm{Ti}, \mathrm{Mg}$, $\mathrm{Fe}$, and $\mathrm{Si}$, and markedly low REE abundances with differentiation. The dikes lie on a mixing trend with a Ca-rich, REE-poor lithology, identical in composition to the Upper Triassic carbonate. Preliminary modeling indicates the dikes have $\sim 3-16 \%$ of an added limestone component. Mineral chemistry and Oisotope systematics are being used to further quantify how much the arc magmas assimilated $\delta^{18} \mathrm{O}$-enriched carbonate, to estimate the physical and chemical transfer of $\mathrm{CO}_{2}$ into the magma.

[1] Lee et al. (2013) Geosphere 9, 21-36. [2] Carter \& Dasgupta (2016) Geochem. Geophys. Geosyst. 17, 3893-3916. [3] Mason et al. (2017) Science 357, 290294. [4] Whitley et al. (2019) Scientific Reports 9, 1-11. 